\title{
Tuning the tide: creating ecological conditions for tidal marsh development in a flood control area
}

\author{
T. Maris $\cdot$ T. Cox $\cdot$ S. Temmerman $\cdot$ \\ P. De Vleeschauwer $\cdot$ S. Van Damme \\ T. De Mulder · E. Van den Bergh • \\ P. Meire
}

(C) Springer Science+Business Media B.V. 2007

\begin{abstract}
The Schelde estuary, characterised as a turbid, polluted and eutrophic system, has nowadays reached a turning point in the restoration of its water quality. During the past century, human activities have reduced the intertidal areas, essential in the estuarine ecosystem for
\end{abstract}

Guest editors: R. Lafite, J. Garnier \& V. De Jonge Consequences of estuarine management on hydrodynamics and ecological functioning

T. Maris $(\varangle) \cdot$ T. Cox $\cdot$ S. Van Damme .

P. Meire

Department of Biology, Ecosystem Management

Research Group, University of Antwerp,

Universiteitsplein 1c, Wilrijk 2610, Belgium

e-mail: tom.maris@ua.ac.be

\section{S. Temmerman}

Centre for Estuarine and Marine Ecology, Netherlands Institute of Ecology (NIOO-KNAW), P.O. Box 140, Yerseke 4400 NT, The Netherlands

P. De Vleeschauwer · T. De Mulder Waterbouwkundig Laboratorium en Hydrologisch Onderzoek, Ministerie van de Vlaamse Gemeenschap, Berchemlei 115, Borgerhout, Antwerpen 2140, Belgium

P. De Vleeschauwer

International Marine \& Dredging Consultants n.v., Wilrijkstraat 37-45, Borgerhout 2140, Belgium

E. Van den Bergh

Instituut voor Natuurbehoud, Kliniekstraat 25,

Brussels 1070, Belgium nutrient cycling and the self-cleaning capacity. Today, in combination with a master plan to protect the population from storm surges, an opportunity rises to restore areas with a tidal influence. One specific option of combining safety and ecology is the creation of flood control areas (FCA) under the influence of a controlled reduced tide (CRT). These specific areas will differ in many ways from fully tidal areas. However, these areas can fulfill important ecological functions with effects on aeration, nitrification, denitrification, sedimentation and primary production in the estuary. Opportunities for ecological development within a CRT have been investigated for a specific case. The ecology within a CRT showed to be very case specific, depending e.g. on the morphology of the area, the sluice design and the local water quality. Depending on the sluice design, water quality can be improved and sedimentation can be influenced. Possible measures to design a CRT with a rich habitat variation are discussed.

Keywords Estuary - Restoration - Regulated tidal exchange $\cdot$ Flood control area

\section{Introduction}

Estuaries are known to be among the most productive ecosystems in the world (Constanza 
et al., 1997; Elliot \& McLusky, 2002). A healthy estuary has a very important structural biodiversity due to the many gradients (fresh-salt; sandsilt; deep channels-irregular flooded marshes). Tidal flats and tidal marshes are essential habitats for many birds, fish, benthos and plants.

Due to a long residence time of the water and the intense interactions between water, soil and atmosphere, tidal areas also play an important role in nutrient cycling and the self-cleaning capacity of estuarine rivers (Middelburg et al., 1995; Mallin \& Lewitus, 2004; Van Damme et al., 2005).

During the past centuries, dike construction and land reclamation for agricultural, urban, industrial or port developments have dramatically reduced the tidal areas throughout the world, both in surface and in quality. Many estuaries suffer from a loss of habitat and degradation, the latter mainly due to anthropogenic pollution (Soetaert et al., 2006). Consequently, the important ecological functions of an estuary are under pressure, leading to e.g. an alteration in the food web in the coastal zones. Changes in the estuarine morphology can cause a substantial rise of the tidal amplitude, often leading to an increased risk for flooding. With respect to global change and sea level rise, protection against storm surges will become more and more important.

Further loss of habitat is now restricted due to legislation and if losses are inevitable they must be compensated for, at least in some parts of the world. In the USA compensation has a strong tradition (Zedler, 2004), but now also in Europe it is a hot topic due to the Habitat (92/43/EEC) and Bird Directive (79/409/EEC) (e.g. Pethick, 2002). Restoration of the estuarine habitat becomes more and more essential. Mostly, this is done by returning land to the estuary, either by managed realignment (i.e. de-embankment) or lowering raised outer dike areas. Some examples (e.g. Sieperdaschor (Eertman et al., 2002)) have proven that nature development after de-embankment can be very fast and successful.

Many estuaries are, however, situated in very densely populated areas with major harbour and industrial activities. As a consequence, land is scarce and expensive, so that managed realignment is unlikely. A new philosophy was needed, combining safety, economy (harbour) and nature. Giving more space to the river through controlled inundation areas offers the opportunity to protect against flooding and restore the ecological functioning of the estuary without obstructing the economic development of neither harbours nor navigation. One specific way to combine ecology and safety is the creation of a flood control area (FCA) with a controlled reduced tide (CRT) (Meire et al., 2005).

The CRT principle can create a favourable tidal regime for tidal wetland restoration in a FCA, regulated by a simple but well-designed system of in- and outlet sluices that needs no further steering, regulating or pumping (Cox et al., 2006) These specific areas however, will differ in many ways from fully tidal wetlands, mainly because of the different flooding regime, which is now also the function of the case specific inlet-outlet sluice design. But besides the tidal regime, also water quality can be a function of the chosen CRT design.

In the highly polluted Schelde estuary, an opportunity rises to restore areas with a tidal influence, in combination with a master plan (Sigma Plan) (Meire et al., 2005) to protect the densely populated catchment area. Cox et al. (2006) investigated the hydraulics of the FCACRT design at Kruibeke (Belgium), one of the first CRT's that will be implemented. This article deals with some major ecological consequences of the FCA-CRT at Kruibeke. A successful coupling of safety and ecology can open many perspectives for the estuary: the destination of about 1500 ha of land is under discussion right now.

\section{Materials and methods}

Study area

The Schelde, with a total length of $350 \mathrm{~km}$ springs in the north of France (near St Quentin), passes through Belgium and the Netherlands, where it has its mouth to the North Sea. The tidal influence of the Schelde estuary reaches up to Gent, $155 \mathrm{~km}$ upstream from the mouth, giving the Schelde estuary (Fig. 1) the unique transition from salt over brackish to freshwater tidal areas (Van 


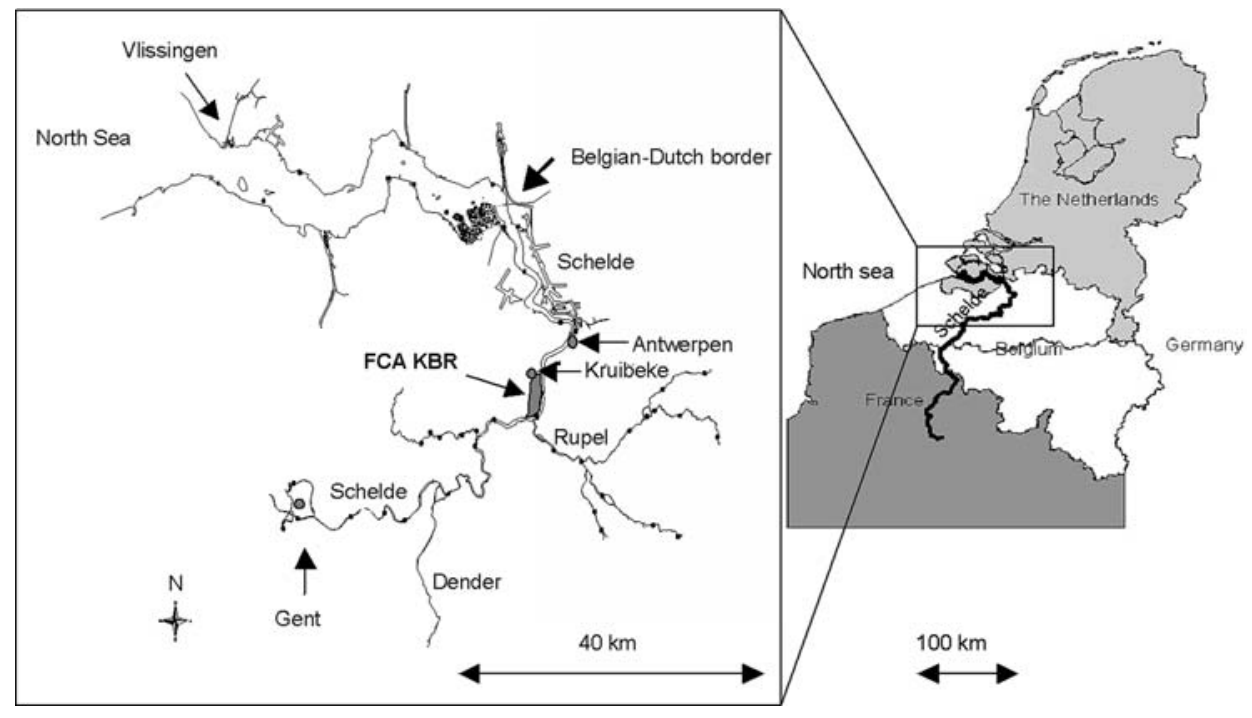

Fig. 1 The Schelde estuary and the location of the CIA KBR (Controlled Inundation Area Kruibeke-Bazel-Rupelmonde)

Damme et al., 2005). This tidal influence, reaching so far inland in the densely populated area of Flanders, resulted in a more than 1000 year old, continuous struggle against flooding. The increasing tidal range forced inhabitants of the lower valley to protect the land by dikes. Driven by economic necessity, land claims and the deepening of the fairway to the port of Antwerpen have further increased the tidal amplitude. The last century, average high tides increased by $0.5 \mathrm{~m}$, low tides decreased by $0.3 \mathrm{~m}$ (Taverniers, in Meire et al., 2005) Tidal curves for neap, mean and spring tide in Kruibeke, approximately $97 \mathrm{~km}$ from the mouth, illustrate a spring-neap tide variation of almost $2 \mathrm{~m}$ (Fig. 2a).

After the disastrous storm flood of 1976 the Belgian government adopted the so called Sigmaplan. Next to heightening and strengthening of dikes and the construction of a storm surge barrier, the implementation of FCA was planned. Twelve FCA's are already implemented, a thirteenth, the FCA KBR, is now under construction. In a revision and actualization of the Sigmaplan, with focus safety, accessibility and ecology, this expensive barrier is under discussion. More FCA, a cheaper solution when the benefits from nature development in these areas are taken in account, can protect the estuary against storm tides with a return period of 4000 years, without the need for the expensive storm surge barrier.
The FCA "Kruibeke-Bazel-Rupelmonde" (KBR) is a polder area of 600 ha along the estuary, with, relative to the river, a very low elevation due to subsidence, whereas sedimentation has lifted the tidal marshes up to the level of mean spring tide. The entire polder was designated for nature compensation: in the south was choosen for a groundwater based nature compensation. The northern part, the Kruibeke polder, needs to compensate for lost tidal wetlands. The low elevation, providing the FCA a huge storage capacity for safety, excludes the introduction of the complete tidal range. This would cause extended periods of flooding, preventing a successful establishment of the most flood tolerant plants (Boumans et al., 2002). Introduction of a reduced tide, with a small tidal range and reduced high water level, should allow tidal wetland development without impairing storage capacity for safety. A simple design of high inlet sluices and low outlet sluices gives a good approximation of a tidal marsh hydrology in the polder (Cox et al., 2006). A permanent opening of one valve in the outlet sluice was chosen to smoothen the tidal curve and allow fish passage. Sluice dimensions are summarized in Table 1.

The Schelde has a long tradition of extensive anthropogenic pollution and is characterised as eutrophic (Soetaert \& Herman, 1995; Struyf et al., 2004; Van Damme et al., 2005). 

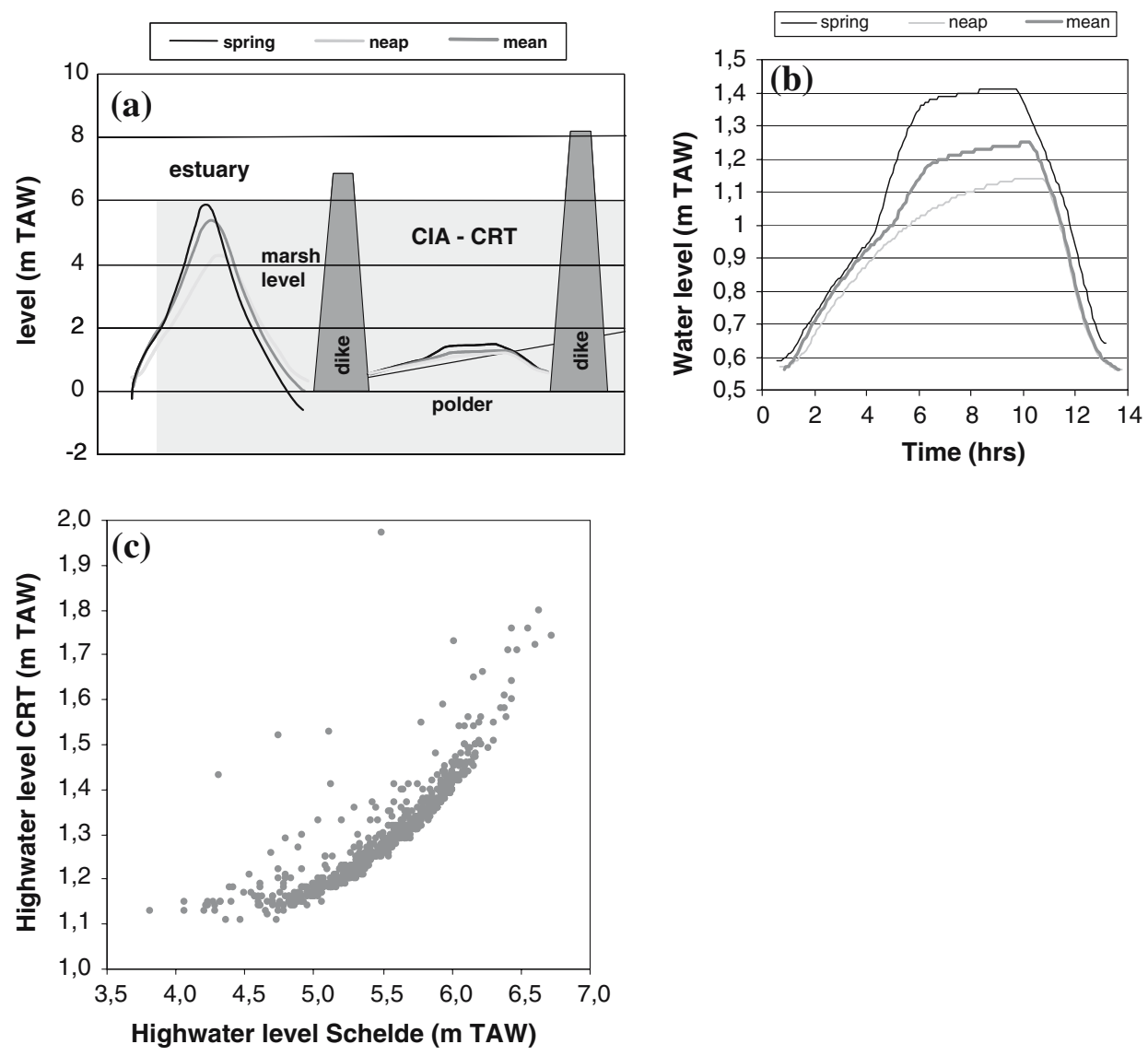

Fig. 2 (a) Mean tidal curves in the Schelde estuary near Kruibeke for spring tide, neap tide and mean tide and a modelled tidal curves for the CIA-CRT, with indication of the elevation of the outer dike tidal marshes, dikes and the inner dike polder level. (TAW $=$ the Belgian reference level, about $0.5 \mathrm{~m}$ above the mean low level of ebb during

Table 1 Sluice dimensions and threshold level used to model the tidal regime

\begin{tabular}{llll}
\hline & Inlet & Inlet & Outlet \\
\hline Position & High & Low & Low \\
Threshold (m TAW) & 4.70 & 0.50 & 0.50 \\
Total width (m) & 18.0 & 1.5 & 45.0 \\
Height (m) & 2.20 & 0.55 & 2.20 \\
Length (m) & 25.0 & 55.0 & 55.0 \\
\hline
\end{tabular}

Notwithstanding large efforts for industrial and municipal wastewater treatment during the last decade in Flanders and other parts of the catchment, water quality is still bad. The pollution in the estuary reaches a climax near the interface between the freshwater and the brackish zone spring tide at Kruibeke). (b) Modelled tidal curves for the CIA-CRT KBR for spring tide, neap tide and mean tide. Time 0 is the moment of low tide in the estuary. (c) Relation between high water levels in the Schelde at Kruibeke and the modelled high water levels in the CIACRT KBR for the year 2000

(approximately $100 \mathrm{~km}$ upstream from the mouth), where the major tributary Rupel delivers the large input of untreated wastewater from the city of Brussels. The FCA KBR is situated $6 \mathrm{~km}$ downstream the mouth of the Rupel (Fig. 1). When during ebb the polluted water of this tributary passes in front of the FCA, the aquatic system in the estuary is nearly anoxic.

Sampling and analysis

Oxygen concentration, turbidity and specific conductivity were measured by means of a 'Hydrolab Datasonde 3' multiprobe logger. This logger measured in the Schelde at Kruibeke, $1 \mathrm{~m}$ below the water surface, between February 1997 and 
August 2003, in weekly sessions at a measuring frequency of 1/15 min. In 1999 the most intensive monitoring was done with 32 weekly sessions equally spread over the year. Samples for suspended matter (SPM) were collected monthly. Suspended matter was determined gravimetrically after filtration on pre-combusted Whatman $\mathrm{GF} / \mathrm{F}$ filters. The turbidity data were related to suspended matter using two linear regressions:

Winter (October-March): SPM (mg/l) = 1.054 turbidity $(\mathrm{NTU})+21.13\left(R^{2}=0.63 ; F_{1,17}=14.07\right.$; $P<0.0001)$

Summer (April-September): SPM $\quad(\mathrm{mg} /$ 1) $=1.207$ turbidity $(\mathrm{NTU})+22.81 \quad\left(R^{2}=0.68\right.$; $\left.F_{1,16}=34.1 ; P<0.0001\right)$

Water levels and elevations are expressed in $\mathrm{m}$ TAW, the reference level used by AWZ (Administratie Waterwegen en Zeewezen, Ministry of the Flemish Government). This reference level is about $0.5 \mathrm{~m}$ above the mean low level of ebb during spring tide.

\section{Modelling}

After a first survey with the model described in Roman et al. (1995) Cox et al. (2006) have determined what sluice configuration suits best for the FCA-CRT to approach a tidal regime similar to the tidal marshes in the Schelde estuary. For the present article, the detailed modelling of the hydrodynamics of the FCA-CRT was done using the hydrodynamic Zeeschelde 1d-model of WLHO (Waterbouwkundig Laboratorium en Hydrologisch Onderzoek) (1DWLHO version 2003). This model takes into account the bathymetry of the polder, hydrodynamic characteristics of the inand outlet sluices and the occurrence of extra water input from a local brook. The flow rates through the sluices are modelled based on the formulas for different flow types described by Bodhaine (1968). Depending on the flow type, the flow rate is calculated in function of the inner and outer dike water level, the water velocity and sluice friction. Flow rate coefficients for the formulas of Bodhaine, specific for the KBR FCA-CRT sluices, were determined using a physical scale model (scale 1:8). Thus, for a time series of water levels in the estuary at Kruibeke (tidal data derived from the continuous data measurements in Vlissingen for the Year 2000) the water levels in the FCA-CRT were deduced.

In order to model sediment accretion in the FCA-CRT, the MARSED model was used. This sedimentation model is extensively described, calibrated and validated against field data for tidal marshes in the Scheldt estuary in Temmerman et al. (2003) and (2004). In essence, the MARSED model simulates sediment deposition and elevation change with time at one point in space, based on a physical formulation of the settling of suspended sediments from the water column that floods the marsh surface. Thus, the main input for the model is the suspended sediment concentration in the flooding water and the frequency-height distribution of tidal inundations. For tidal marshes, the model accounts for a negative feedback between sediment accretion and tidal inundation. However, for a CRT the resulting rise of the polder elevation is not affecting the tidal volume, for reasons that will be discussed later, so that no feedback between sediment accretion and tidal inundation was used for modelling the CRT. Instead, a constant sediment accretion rate is expected in a CRT. As input for the model, the settling velocity of suspended matter was estimated at $0.0001 \mathrm{~m} / \mathrm{s}$, the dry bulk density of deposited sediments at $450 \mathrm{~kg} / \mathrm{m}^{3}$ (both based on field data from tidal marshes in the Scheldt estuary: Temmerman et al., 2004). Two scenarios were simulated, using an inlet sluice at $3 \mathrm{~m}$ TAW (scenario 1) and $4.7 \mathrm{~m}$ TAW (scenario 2). For both scenarios the input tidal inundation regime was based on the hydrodynamic modelling mentioned above. The corresponding suspended matter concentration (SPM) in the inflow was estimated at $120 \mathrm{mg} / \mathrm{l}$ (scenario 1) and $144 \mathrm{mg} / \mathrm{l}$ (scenario 2) (yearly averages based on our sampling program). A sensitivity analysis was carried out for the three crucial input variables: the settling velocity of suspended matter, the dry bulk density of deposited sediment and SPM. Since SPM had the biggest influence on model output, error bars were calculated using the standard deviations on the yearly averaged SPM.

The oxygen gain $(G)$ when river water splashes down constructed cascades at the inlet was calculated as (Mosselman et al., written 
communication): $G=\left(C_{\mathrm{s}}-C_{0}\right) \cdot(1-1 / r)$, the saturation deficit $\left(C_{\mathrm{s}}-C_{0}\right)$ being the difference between oxygen saturation concentration $\left(C_{\mathrm{s}}\right)$ and initial oxygen concentration $\left(C_{0}\right)$; the deficit rate for overflows $r=1+0.34 \cdot a \cdot b \cdot(1+0.046 T) . \Delta h$; a is a coefficient for water quality ( $a=1$ for polluted water); $b$ is a coefficient for the kind of overflow ( $b=1.3$ for cascades); $T$ is water temperature in ${ }^{\circ} \mathrm{C} ; \Delta h$ is the differential head. In the CRT the differential head was the difference in height between the threshold of the inlet sluice and the polder elevation.

Atmospheric reaeration is modelled with the equations of Baretta \& Ruardij (1988). In the calculations the empirically determined oxygen transfer coefficient of $0.96 \mathrm{~m} /$ day, implemented by Baretta \& Ruardij (1988) for the Ems estuary, was used.

\section{Results}

Tidal regime

The combination of high and low in- and outlet sluices will strongly reduce the tidal regime in the polder compared to the estuary, but still allows a spring tide-neap tide variation of about $30 \mathrm{~cm}$

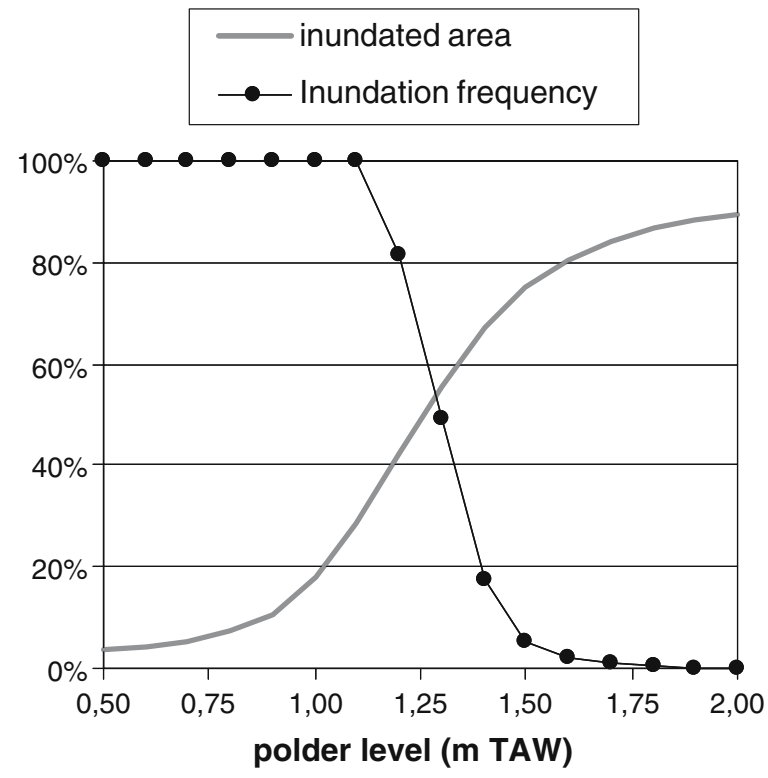

Fig. 3 Inundated area and inundation frequency in the CIA-CRT. Modelling was done using the water level data of the entire year 2000
(Fig. 2a, b). The high water level in the polder will fluctuate between 1.1 and $1.4 \mathrm{~m}$ TAW (Fig. 2b), resulting in a wide range of inundation frequencies in the inundation area (Fig. 3). Higher water levels, close to $2 \mathrm{~m}$ TAW will also occur in the CRT. As can be noticed on Fig. 2c, higher flood levels in the CRT do not always correspond with high flood levels in the estuary. These deviant water levels are not only due to a high flood level in the estuary, but will depend mainly on the water level of the previous ebb. When the ebb level is high, evacuation of the CRT water can only take place during a short period, leading to an incomplete drainage of the CRT. In combination with a high discharge input in the CRT from a local brook (Barbierbeek), this can result in higher water levels during the next flood. Since the water level never passed $2 \mathrm{~m}$ TAW in our modelling, this causes no problem for the storage capacity and safety function of the FCA.

Although the reduced tide will result in water depths in the FCA that are similar to the water depths observed on the tidal marshes in front of the CRT, still some major hydraulic differences remain. As can be deduced from Fig. 2a, the spring-neap tide variation in the CRT will be smaller. The time that the tide in the estuary exceeds the level of the outer dike marshes is very short. In the CRT on the contrary, the flooding of the polder area will be significantly longer, whereas the inundation height will be lower. The outer dike marshes also face the high dynamics and strong current of the Schelde river; in the CRT these dynamics will also be strongly reduced.

In Kruibeke, a tidal asymmetry can be observed in the estuary. Especially during spring tide the flood rises faster, the recessing of the tide takes about $1 \mathrm{~h}$ more. In the CRT, an opposite phenomenon will be observed: depending on the sluice configuration it can take about 3 times longer to fill the polder to the high water level than to evacuate the water out again (Fig. 2b).

\section{Water quality}

Choosing a high inlet sluice is necessary to obtain a suitable variation in inundation frequencies due to differences between spring and neap tides. The 


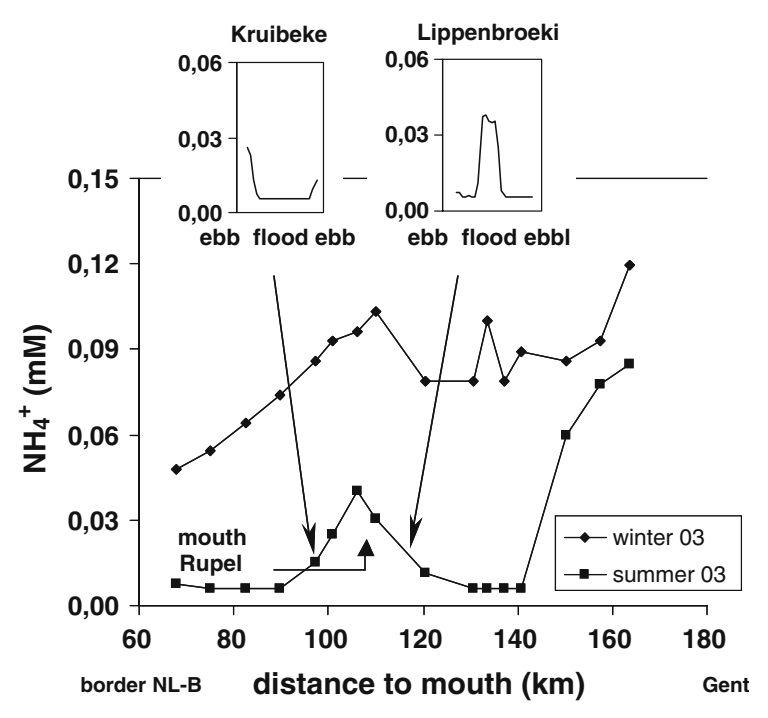

Fig. 4 Tidal ammonia fluctuations upstream (Lippenbroek) and downstream (Kruibeke) the Rupel for 2003 and the ammonia gradient along the estuary causing this tidal patterns

choice of a high inlet sluice will also determine largely the water quality. Indeed, water quality fluctuates with the tides. Besides the tidal fluctuation of salinity, oxygen and e.g. ammonia (Fig. 4) show clear tidal patterns, caused by the occurrence of the polluted tributary Rupel upstream Kruibeke. Sites upstream the Rupel display an opposite tidal concentration profile for e.g. ammonia (Fig. 4).

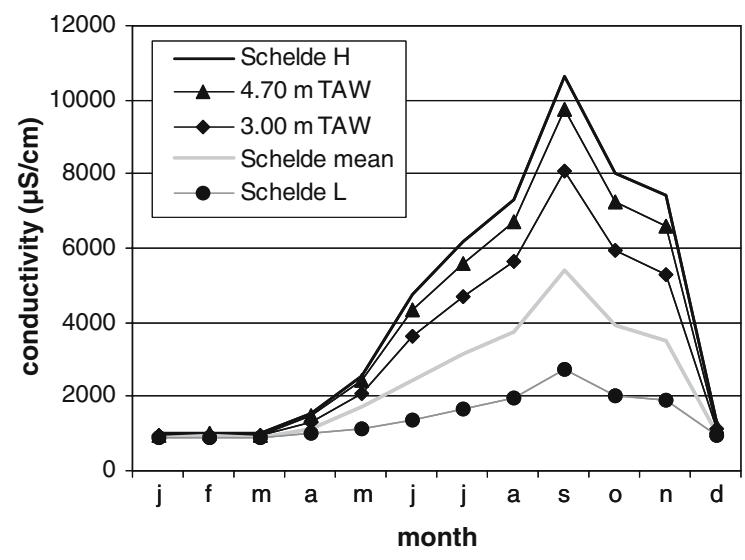

Fig. 5 Mean conductivity at the CRT inlet sluice in function of threshold level. Mean conductivity (Schelde mean), conductivity at high tide (Schelde $\mathrm{H}$ ) and low tide (Schelde L) in the estuary at Kruibeke
Conductivity

Conductivity alters near Kruibeke in summer from $2000 \mu \mathrm{S} / \mathrm{cm}$ (ebb) to $10,000 \mu \mathrm{S} / \mathrm{cm}$ (flood) (Fig. 5), with peaks up to almost $20,000 \mu \mathrm{S} / \mathrm{cm}$ (when spring tide occurs during a period with very low discharges, data not shown). Since the CRT will only be filled close to the moment of high tide, when the water level has passed the $4.70 \mathrm{~m}$ TAW threshold, the conductivity of the incoming water will not represent the mean conductivity of the Schelde near Kruibeke. The higher the threshold level of the inlet sluice, the higher the conductivity will be of the inflow (Fig. 5), leading to a mean conductivity that is substantially higher than the mean conductivity in the estuary near Kruibeke. This difference emerges dramatically in summer, but not in winter. Whereas in the estuary the conductivity drops at low tide in summer, it will remain at the level of high tide in the CRT since there is no strong ebb flow of fresh water passing though the polder. In the outer dike situation in front of the CRT, the tidal flats are washed with freshwater. In the CRT on the contrary, the brackish water will only be evacuated during ebb, from the CRT to the estuary. Thus, at high tide, the CRT and the estuary will have comparable conductivity; the estuary even faces a bit higher conductivity at the moment of high water since the conductivity in the CRT at high water is a mixture of all the water coming in since the tide has passed the sluice threshold. During ebb on the contrary, no more estuarine water will enter the CRT (except for the water from a local brook) so that conductivity remains at the same high level of high water while the polder is running empty. This high conductivity will thus represent a conductivity typical for tidal flats that can be found some $20 \mathrm{~km}$ downstream of Kruibeke. During the winter, the strong discharge flow reduces the tidal salinity variation almost completely in Kruibeke; in the CRT no remarkable difference in conductivity will be observed (Fig. 5).

\section{Oxygen concentration}

Also the oxygen concentration shows a tidal pattern in the Schelde estuary near Kruibeke. The occurrence of the very polluted major 


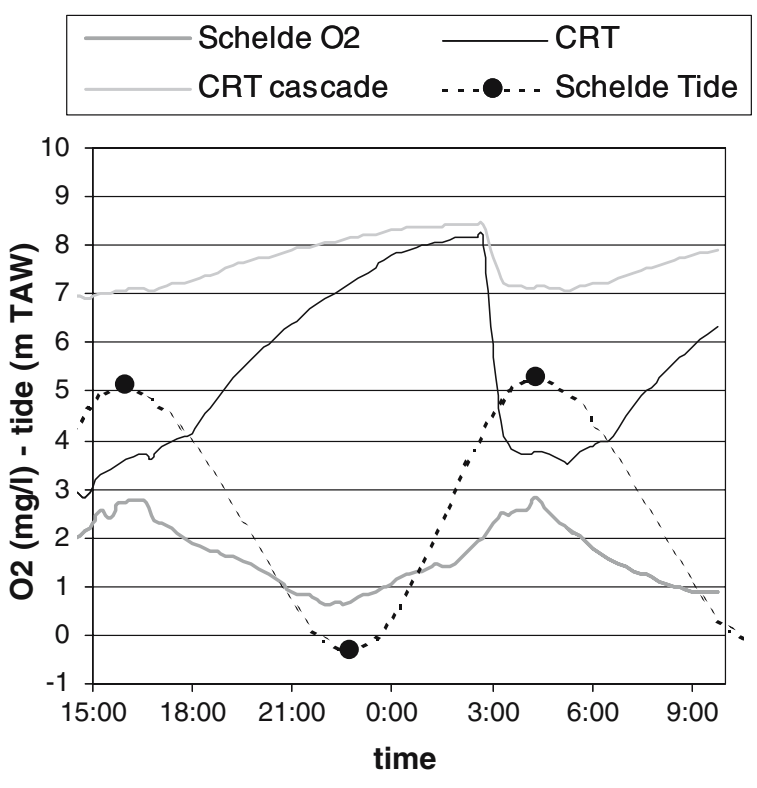

Fig. 6 Tidal oxygen patterns: Schelde O2: monitoring data of a typical summer day (27-28/7/1999); CRT: modelled oxygen pattern in the CIA, only using surface aeration; CRT cascade: modelled oxygen pattern, both aeration though cascades and surface aeration are taken in account; Levels of high and low tide are indicated (Schelde tide)

tributary, the Rupel, causes a clear drop in the oxygen concentration during the ebb flow (Fig. 6). During flood pollution keeps the oxygen level between $2 \mathrm{mg} / \mathrm{l}$ and $4 \mathrm{mg} / \mathrm{l}$ in summer, but at low tide the oxygen concentration mostly does not exceed $1 \mathrm{mg} / \mathrm{l}$. Using high inlet sluices, this nearly anoxic water will not enter the CRT. The differential head between inlet and polder level even offers an opportunity to gain oxygen while the water enters the CRT. By creating a series of cascades, the incoming water can be aerated. The higher the inlet sluice, the bigger the gain, but even with a differential head of only $1.3 \mathrm{~m}$ and a water temperature of $25^{\circ} \mathrm{C}$ an important gain can be achieved (Table 2). With lower water temperatures this gain is higher (Table 2).

Even without cascade system, oxygen saturation will be higher in the CRT than in the estuary (Fig. 6). Physical surface aeration can slowly lift the oxygen concentration to about $80 \%$.

\section{Suspended matter concentration}

Suspended matter concentration shows a clear seasonal and tidal fluctuation (Fig. 7). At high 


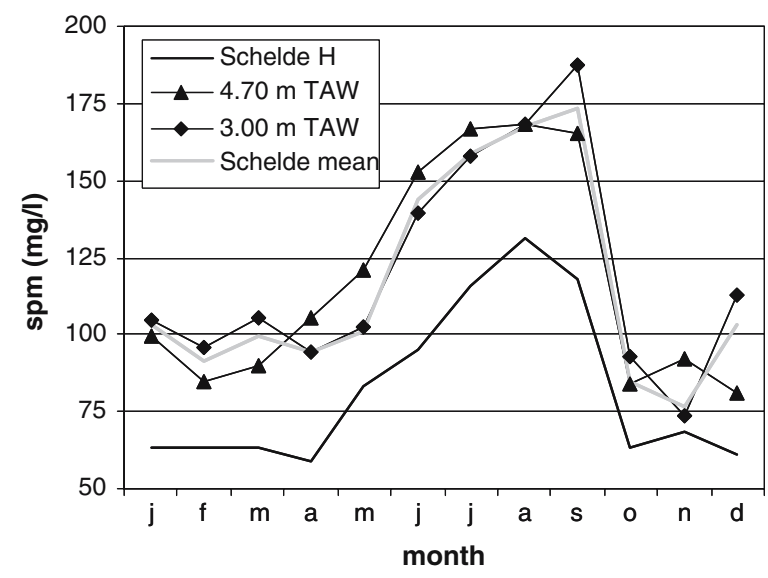

Fig. 7 Mean suspended matter (spm) concentration at CRT inlet sluice in function of threshold level. Mean spm (Schelde mean) and spm at high tide (Schelde $\mathrm{H}$ ) in the estuary at Kruibeke

tide, suspended matter starts settling, resulting in a very low turbidity at the moment of slack water. This period of low turbidity is relatively short (10-15 min), preceded and followed by a phase with the highest current velocity and highest turbidity. The average turbidity of the Schelde when the water level passed the $4.70 \mathrm{~m}$ TAW threshold is not much different from the mean turbidity during the entire tidal cycle. The mean sediment concentrations at the inflow of the CRT for different threshold levels studied here are thus all comparable to the mean sediment concentration in the estuary itself (Fig. 7). Very high inlet sluices allowing e.g. only the less turbid water during the short phase of springtide high water can strongly affect the sediment concentration at the inflow, but this would have a severe impact on the tidal regime (and ecological development) and was thus not considered.
Sedimentation

First, sedimentation was estimated based on mass balance calculations. Different sluice configurations, giving different tidal regimes, will alter the incoming water volume, and as a consequence the imported sediment mass. Table 3 shows the imported sediment mass in function of the mean water level. Without sediment export, a mean water level of about $1.3 \mathrm{~m}$ TAW would result in an accretion of $28 \mathrm{~kg} \mathrm{year}^{-1} \mathrm{~m}^{-2}$, or about $6 \mathrm{~cm} \mathrm{yr}^{-1}$ (mean sediment density $450 \mathrm{~kg} \mathrm{~m}^{-3}$ ). The Breebaart polder, a polder recently connected to the Dollard estuary (Netherlands) through a culvert, also faces a strongly reduced tide. In this polder, receiving comparable SPM concentrations $\left(120 \mathrm{mg} \mathrm{l}^{-1}\right)$, about $45 \%$ of the incoming sediment was retained (Pelletier et al., 2004). In the CRT KBR, this would result in about $13 \mathrm{~kg}_{\text {year }}{ }^{-1} \mathrm{~m}^{-2}$ or $2.8 \mathrm{~cm}_{\text {year }}{ }^{-1}$. This is almost twice the sedimentation rate recorded by Wartel \& Franken (written communication) on the brackish marshes in de Schelde. Temmerman et al. (2003) recorded sedimentation rates varying between $1 \mathrm{~cm} /$ year and $2 \mathrm{~cm} /$ year along the Belgian Schelde.

Secondly, the sedimentation rate in the CRT was modelled using the MARSED model for two different sluice configurations (Fig. 8). It was clear that a higher mean water level resulted in higher sedimentation rates. For a mean high water level of $1.3 \mathrm{~m}$ TAW, this model predicts a rather slow accretion above $1.2 \mathrm{~m}$ TAW (2/3 of the polder area). The fact that this model was calibrated for tidal marshes on the Schelde estuary itself might explain the lower sedimentation rates predicted by the model compared to the mass balance calculation above. In the CRT, the strongly reduced hydrodynamics may enhance the settling of sediment, which may result
Table 3 Sediment import, calculated for an average incoming sediment concentration of $140 \mathrm{mg} / \mathrm{l}$

\begin{tabular}{lllll}
\hline $\begin{array}{l}\text { Water level } \\
(\mathrm{m} \mathrm{TAW})\end{array}$ & $\begin{array}{l}\text { Inundated } \\
\text { surface }(\mathrm{ha})\end{array}$ & $\begin{array}{l}\text { Water volume } \\
\left(10 \mathrm{e} 6 \mathrm{~m}^{3}\right)\end{array}$ & \multicolumn{2}{l}{ Sediment import } \\
\cline { 4 - 5 } & & & $\left(\mathrm{kg} / \mathrm{year} / \mathrm{m}^{2}\right)$ \\
\hline 1.8 & 137 & 0.847 & 84209 & 61 \\
1.4 & 106 & 0.346 & 34434 & 33 \\
1.3 & 88 & 0.249 & 24777 & 28 \\
1.1 & 45 & 0.117 & 11589 & 26 \\
\hline
\end{tabular}




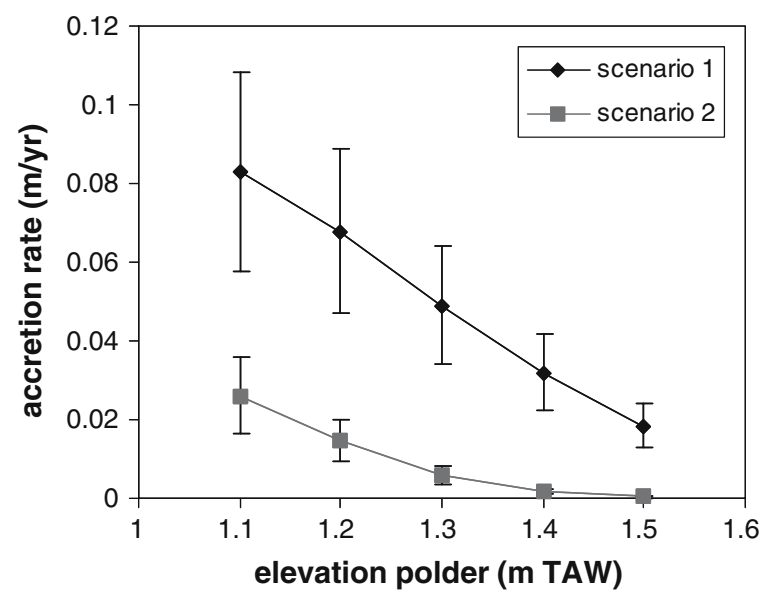

Fig. 8 initial sedimentation rate for two possible tidal regimes. Scenario 1 figures the accretion for sluice configurations giving a mean high water level at $1.6 \mathrm{~m}$ TAW and a springtide high water level at $1.8 \mathrm{~m}$ TAW. Scenario 2 gives accretion when mean high water at $1.3 \mathrm{~m}$ TAW and springtide high water at $1.5 \mathrm{~m}$ TAW

in a higher accretion rate compared to tidal marshes. The evolution of sedimentation patterns on a longer term (more than a few years) and the change in storage capacity are difficult to predict. Models to predict sedimentation on outer dike marshes have already proven to be accurate for the Schelde estuary (Temmerman et al., 2003, 2004), but they are probably not suited to predict long-term sedimentation in a CRT. Outer dike sedimentation leads to a higher marsh elevation, and thus reduced inundation frequency. This in turn will reduce sedimentation and an equilibrium elevation of the marsh can be achieved. In the CRT on the contrary, the water volume and sediment load coming in will be independent of the surface elevation of the polder but only rely on the dimensions of the sluices. The sluice configuration will determine the tidal regime in the CRT. Unless changes are made at the sluice construction, the tidal volume entering the CRT will remain the same, regardless of any change in the polder morphology or elevation. Sedimentation will not automatically reduce the inundation frequency, but might even cause an increase in inundated area, when the same water volume will be spread over a smoothened surface.

\section{Discussion}

Using a combination of sluices can create a reduced tide in an enclosed area (Roman et al., 1995). Cox et al. (op. cit.) modelled that with a combination of high inlet and low outlet sluices this is also possible in a polder area with very low elevation, but this reduced tidal regime differs in many ways from the tidal characteristics observed on the outer dike tidal areas. Examples have shown that an altered tidal regime does not necessarily obstruct tidal marsh development (e.g. Breebaart polder, Netherlands (Pelletier et al., 2004). The situation in a CRT however will differ substantially from other areas with a reduced tide, since here the use of high inlet and low outlet sluices will alter some typical tidal relations e.g. the relation between inundation frequency, marsh elevation and sedimentation.

The position of high and low in- and outlet sluices not only influences the tidal regime and thus the ecology in the CRT, it will alter the water quality as well. The water quality in the CRT we studied will not be the same as the mean quality found on the outer dike intertidal areas in front of the CRT. Especially the conductivity, but also nutrient concentrations will differ since the estuary show tidal fluctuations at Kruibeke for e.g. ammonia (Fig. 4), nitrate or phosphorous (data not shown). Depending on the sluice threshold, the mean conductivity in summer in the CRT will be higher, and the big tidal fluctuation that can be observed in the estuary will almost completely disappear, resulting in a rather constant level of high conductivity.

\section{CRT design}

The alteration in water quality, with possible effects on the marsh development, had however little influence on the choice of the inlet constructions. The sluice levels were determined in the first place to create a favourable tidal regime. When designing a CRT, the safety aspect is also prominent. If safety and the conservation of storage capacity was not an issue, managed realignment might be a better solution. Now measures have to be taken to avoid the loss of storage capacity. This causes some restrictions for 
the sluice design, since the latter will determine the sedimentation rate in a CRT. A higher water level results in an increase in sediment import. The amount of sediment that will remain in the CRT is uncertain. For the development of a tidal marsh ecosystem this sedimentation is however wanted. But this is in conflict with safety.

To preserve maximal storage capacity, sedimentation should be reduced to a minimum. There are two ways of doing this: reducing the input and maximising the output. Input reduction means a reduction of the tidal volume and the dynamics of the tidal marsh ecosystem. This balance between ecology and safety will be a political decision. Maximising output will be the goal, but with the current knowledge it is difficult to predict the impact of the design options.

To maximise the output, we tried to maximise the tidal energy during ebb in the CRT. This will be done in two ways. First, all outlet sluices were concentrated in one place to concentrate all tidal energy (Fig. 9). Second, by reducing the time of

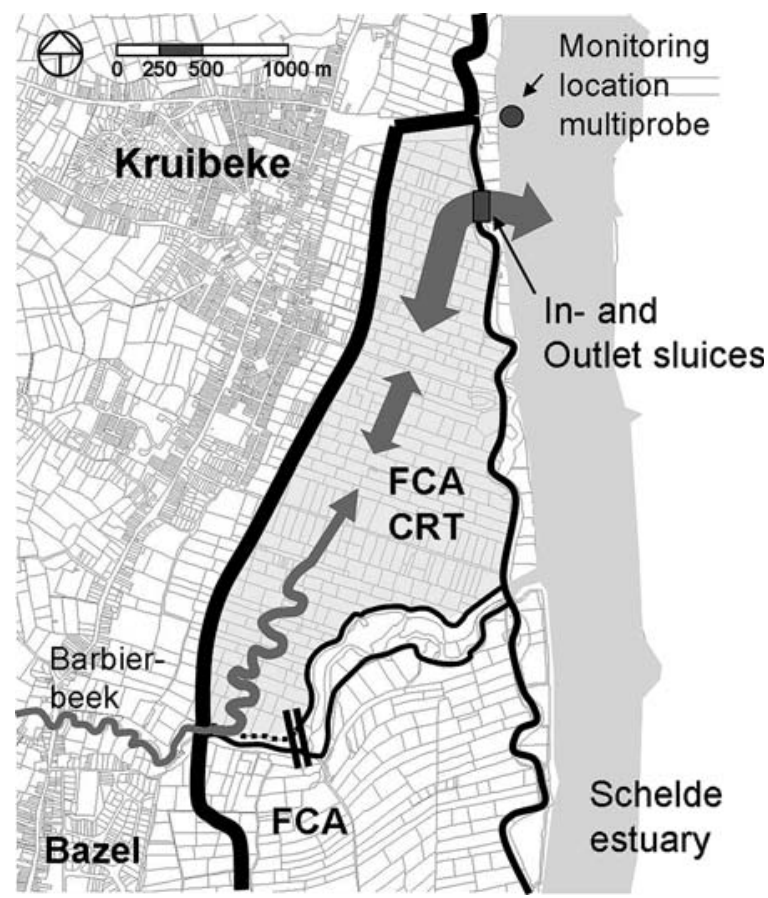

Fig. 9 Possible measures to design a CRT. All in- and outlet sluices are concentrated in the north of the polder. In the south, a small freshwater brook (Barbierbeek) is liberated from its former bed and can freely find its way to the outlet sluices ebb in the CRT, the tidal asymmetry was enforced (Fig. 2b). This will result in a "reversed" tidal pumping effect: during flood the sediment enters slowly the CRT and will probably not be transported far inside the polder area but will settle in the creek close to the sluices. During the short period of ebb, the strong outgoing current should export some recently deposited materials out of the creek.

Additionally, a sediment poor freshwater brook (Barbierbeek) will be deviated through the polder (Fig. 9). The brook enters the CRT in the south, whereas the sluices are situated in the north.

\section{Ecological impacts}

Although the mean conductivity will be higher in the CRT, we do not expect a big influence on the marsh vegetation. The outer dike marsh vegetation, only growing above a certain elevation (approximately $5.50 \mathrm{~m}$ TAW, the level of mean high water) is flooded with the same brackish water. More influence might be expected from the tidal regime and altered inundation time and inundation height. Boumans et al. (2002) note that a tidal regime, well designed for the desired marsh vegetation, is crucial for successful restoration, but that effects of an altered tidal prism or altered accretion are less obvious. Observations of Zonneveld (1960) and Jans (written communication) in the Biesbosch show that when the inundation height is reduced, vegetation can grow at places with a higher inundation frequency. Experiments in an artificial mesocosm experiment that simulates the tide in a CRT, indicate that a prolonged inundation time is not obstructing vegetation development, at least not for reed (Phragmites australis) (Van Regenmortel, personal communication), the dominant species on the outer dike marshes near Kruibeke. A colonisation of reed on the marshes in the CRT can thus be expected. The appearance of distinctive patterns of plant species, along elevation or salinity gradients is not expected rapidly because of preexisting soil properties (Boumans et al., 2002). However, changes in soil properties, due to inundation and sedimentation, will lead to plant patterns caused by the differences in salinity, 
elevation or competition, at least when seeds sources of appropriate species are non-limiting.

The situation on tidal flats in a CRT on the other hand will be completely different. No flooding with a fresh ebb stream will result in more brackish tidal flats. Therefore the ecology on these tidal flats will probably differ greatly from the outer dike tidal flats, even from tidal flats more downstream that are flooded with water of a comparable mean conductivity. The tidal flats in the brackish part of the estuary have to deal with high dynamics: a very big tidal fluctuation in salinity, high turbidity and a strong current. Only few benthos species can survive here (Ysebaert et al., 1993). In the CRT on the contrary, tidal fluctuation will be minimal, turbidity will be reduced and the current will be very low. Such situations normally do not occur in the Zeeschelde, so a prediction of the future benthos population is not obvious.

The introduction of the fresh Barbierbeek will restore a bit of the tidal conductivity fluctuation in the CRT. At the inlet sluice of this brook, this will create a local zone of freshwater and a salinity gradient towards the brackish incoming estuarine water. In this way, during ebb, the influence of the freshwater will increase a resulting in a small zone with tidal fluctuations. The influence of the freshwater will only be noticeable in the south where the Barbierbeek enters the CRT, since discharge of this brook is relatively small compared to the incoming tidal water; at mean discharge of the Barbierbeek $\left(0.35 \mathrm{~m}^{3} \mathrm{~s}^{-1}\right)$ the fraction of this freshwater in the CRT varies between $2.5 \%$ and $10 \%$, depending on the tidal volume entering the polder.

Oxygen concentration will be high in the CRT. Problems of anoxia will never occur in the CRT. Preliminary calculations with an ecosystem model of the Schelde, in which also primary productivity and degradation of detritus is modelled, give similar results for the oxygen pattern in the CRT. Without cascades oxygen poor estuarine water enters the CRT, but will be aerated close to $100 \%$ saturation by the time it is returned to the estuary. With cascades, the water will be aerated immediately; on a sunny day in summer, primary production could even cause an over saturation.
The estuary might benefit from the exchange of the oxygen rich water of the polder. If many CRT's could be attached to the estuary this could have a serious impact on the estuarine water quality. A small rise in the oxygen concentration can have a big influence on the nitrogen cycling. In the very polluted Schelde estuary, nitrogen removal is completely dominated by denitrification in the oxygen poor water column (Soetaert \& Herman, 1995). An increase in oxygen concentration will decrease the pelagic denitrification rate. On the other hand, increasing the surface of tidal marshes and tidal flats will enhance benthic denitrification. In the light of a future improvement of water quality and oxygen saturation, a sustainable long-term solution for the nitrogen removal consists an increase of the intertidal areas. CRT's are one way of doing this.

\section{Conclusion}

The ecology in the CRT KBR will differ substantially from the outer dike marshes in Kruibeke. Besides the aberrations on the tidal curve, that seem to be intrinsic to the CRT system, the altered water quality could play an important role. The difference in mean water quality between CRT and the estuary will depend on the use of high inlet sluices and the position of the CRT in the estuary. High inlet sluices reduce the tidal fluctuation to a rather constant water quality of high water. In Kruibeke, situated in zone with a sharp salinity gradient, this results in more brackish tidal flats in the CRT. Since KBR is located downstream the Rupel, an important source of nutrients and pollution, the quality of the incoming water in the CRT will be better than the average in the estuary in front of the polder. In a CRT upstream the Rupel, this would be the opposite.

Therefore, there will be no general rule to design or predict the ecology of a CRT. Differences in elevation and bathymetry of the CRT and differences in the tidal regime of the estuary will require different sluice design. Water quality and sedimentation will require different solutions. With the right design, suitable conditions for 
marsh development can be achieved. But every different location will need a different CRT design.

Acknowledgements All water samples were analysed in the "UA (University of Antwerpen), Department of Biology, Testing Laboratory for Chemical Water Quality" by Lieve Clement, Eva De Bruynn and Joke Govaerts. Monthly monitoring samples were taken from the "MS Veremans" (AWZ, division Maritime Schelde) in the frame of the OMES (Research Environmental Effects Sigmaplan)-project. We also thank AWZ for supplying all tide measurement data, the financers of the OMESmonitoring project and the Fund for Scientific Research for funding the Scientific Community 'Ecological characterization of European estuaries, with emphasis on the Schelde estuary' (project nr. W 10/5 - CVW.D 13.816), and for funding Dutch-Flemish ecological research projects on the Schelde (project nr. G.0439.02).

\section{References}

Baretta, J. \& P. Ruardij, 1988. Tidal flat estuaries: simulation and analysis of the Ems Estuary. Ecological Studies, Vol. 74. Springer-Verlag, Berlin Heidelberg New York, 101-104.

Bodhaine, G. L., 1968. Chapter A3-Measurement of peak discharge at culverts by indirect methods; Book 3-Applications of Hydraulics; US Geological Survey.

Boumans, R. M. J., D. M. Burdick \& M. Dionne, 2002. Modelling habitat change in salt marshes after tidal restoration. Restoration Ecology 10: 543-555.

Constanza, R., R. D'Arge, R. de Groot, S. Farber, M. Grasso, B. Hannon, K. Limburg, S. Naeem, R. V. O’Neill, J. Puarelo, R. G. Raskin, P. Sutton \& M. van den Belt, 1997. The value of the world's ecosystem services and natural capital. Nature 387: 253-260.

Cox, T., T. Maris, P. De Vleeschauwer, T. De Mulder, K. Soetaert \& P. Meire, 2006. Flood control areas as an opportunity to restore estuarine habitat. Ecological Engineering 28: 55-63.

Eertman, R. H. M., B. A. Kornman, E. Stikvoort \& H. Verbeek, 2002. Restoration of the Sieperda Tidal Marsh in the Scheldt Estuary, The Netherlands. Restoration Ecology 10: 438-449.

Elliott, M. \& D. S. McLusky, 2002. The need for definitions in understanding estuaries. Estuarine Coastal Ans Shelf Science 55: 815-827.

Mallin, A. M. \& A. L. Lewitus, 2004. The importance of tidal creek ecosystems. Journal of Experimental Marine Biology and Ecology 298: 145-149.

Meire, P., T. Ysebaert, S. Van Damme, E. Van den Bergh, T. Maris \& E. Struyf, 2005. The Scheldt estuary: a description of a changing ecosystem. Hydrobiologia 540: 1-11.
Middelburg, J. J., G. Klaver, J. Nieuwenhuize \& T. Vlug, 1995. Carbon and Nitrogen cycling in intertidal sediment near Doel, Scheldt estuary. Hydrobiologia 311: 57-69.

Pelletier, H., H. Wanningen, B. Speelman \& P. Esselink, 2004. Resultaten van een gedempt getijdenregime in polder Breebaart. De Levende Natuur 105: 191-194.

Pethick, J., 2002. Estuarine and tidal wetland restoration in the United Kingdom: policy versus practice. Restoration Ecology 10: 431-437.

Roman, C. T., R. W. Garvine \& J. W. Portnoy, 1995. Hydrologic modeling as a predictive basis for ecological restoration of salt marshes. Environmental Management 19: 559-566.

Soetaert, K. \& P. Herman, 1995. Nitrogen dynamics in the Westerschelde estuary (SW-Netherlands) estimated by means of an ecosystem model (MOSES). Hydrobiologia 311: 225-246.

Soetaert, K., J. J. Middelburg, P. Meire, S. Van Damme \& T. Maris, 2006. Long-term change in dissolved inorganic nutrients in the heterotrophic Scheldt estuary (Belgium, the Netherlands). Limnology and Oceanography 51: 409-423.

Struyf, E., S. Van Damme \& P. Meire, 2004. Possible effects of climate change on estuarine nutrient fluxes: a case study in the highly nutrified Schelde estuary (Belgium, The Netherlands). Estuarine, Coastal and Shelf Science 60: 649-661.

Temmerman, S., G. Govers, P. Meire \& S. Wartel, 2003. Modelling long-term tidal marsh growth under changing tidal conditions and suspended sediment concentrations, Scheldt estuary, Belgium. Marine Geology 193: 151-169.

Temmerman, S., G. Govers, S. Wartel \& P. Meire, 2004. Modelling estuarine variations in tidal marsh sedimentation: response to changing sea level and suspended sediment concentrations. Marine Geology 212: 1-19.

Van Damme, S., E. Struyf, T. Maris, T. Ysebaert, F. Dehairs, M. Tackx, C. Heip \& P. Meire, 2005. Spatial and temporal patterns of water quality along the estuarine salinity gradient of the Scheldt estuary (Belgium and The Netherlands): results of an integrated monitoring approach. Hydrobiologia 540: 2945.

Ysebaert, T., P. Meire, D. Maes \& J. Buijs, 1993. The benthic macrofauna along the estuarine gradient of the Schelde estuary. Netherlands Journal of Aquatic Ecology 27: 327-341.

Zedler, J. B., 2004. Compensating for wetland losses in the United States. Ibis 146(Suppl 1): 92-100.

Zonneveld, I. S. (1960). De Brabantse Biesbosch. Een studie van bodem en vegetatie van een zoetwatergetijdendelta. (The Brabantse Biesbosch. A study of soil and vegetation of a freshwater tidal delta) Pudoc, Wageningen (in Dutch). 